\title{
Article \\ Experimental Validation of the MRcollar: An MR Compatible Applicator for Deep Heating in the Head and Neck Region
}

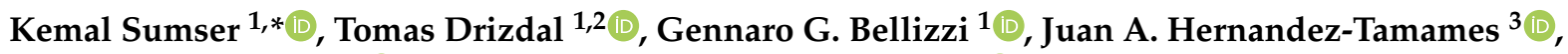 \\ Gerard C. van Rhoon ${ }^{1}$ (D) and Margarethus Marius Paulides ${ }^{1,4}$ (D) \\ 1 Department of Radiotherapy, Erasmus Medical Center Cancer Institute, \\ 3015 GD Rotterdam, The Netherlands; tomas.drizdal@fbmi.cvut.cz (T.D.); \\ gennarobellizzi@gmail.com (G.G.B.); g.c.vanrhoon@erasmusmc.nl (G.C.v.R.); m.m.paulides@tue.nl (M.M.P.) \\ 2 Department of Biomedical Technology, Czech Technical University in Prague, nam. Sítna 3105, \\ 27201 Kladno, Czech Republic \\ 3 Department of Radiology and Nuclear Medicine, Erasmus Medical Center Cancer Institute, \\ 3015 GD Rotterdam, The Netherlands; j.hernandeztamames@erasmusmc.nl \\ 4 Department of Electrical Engineering, Eindhoven University of Technology, \\ 5612 AZ Eindhoven, The Netherlands \\ * Correspondence: k.sumser@erasmusmc.nl
}

check for updates

Citation: Sumser, K.; Drizdal, T.; Bellizzi, G.G.; Hernandez-Tamames, J.A.; van Rhoon, G.C.; Paulides, M.M. Experimental Validation of the MRcollar: An MR Compatible Applicator for Deep Heating in the Head and Neck Region. Cancers 2021, 13, 5617. https://doi.org/10.3390/ cancers13225617

Academic Editor: Takahito Nakajima

Received: 1 October 2021

Accepted: 8 November 2021

Published: 10 November 2021

Publisher's Note: MDPI stays neutral with regard to jurisdictional claims in published maps and institutional affiliations.

Copyright: (c) 2021 by the authors. Licensee MDPI, Basel, Switzerland. This article is an open access article distributed under the terms and conditions of the Creative Commons Attribution (CC BY) license (https:// creativecommons.org/licenses/by/ $4.0 /)$.
Simple Summary: Hyperthermia treatments where tumor tissue is heated to $40-44{ }^{\circ} \mathrm{C}$ for $60-90 \mathrm{~min}$ can be hampered by a lack of accurate temperature monitoring. To solve this need, we have designed an MR compatible head and neck hyperthermia applicator: the MRcollar. In this work, we experimentally validated the design, heating capabilities and the MR compatibility of the MRcollar. The MRcollar antennas efficiently transfer the power and have low interaction between the antenna elements. The heating and focusing capabilities satisfy the requirements. The MRcollar can operate in an MR scanner and it can acquire higher quality MR images due to the built in receiver elements. The MRcollar has great potential to improve hyperthermia treatment in the head and neck region and it is now ready for in vivo studies.

Abstract: Clinical effectiveness of hyperthermia treatments, in which tumor tissue is artificially heated to $40-44{ }^{\circ} \mathrm{C}$ for $60-90 \mathrm{~min}$, can be hampered by a lack of accurate temperature monitoring. The need for noninvasive temperature monitoring in the head and neck region (H\&N) and the potential of MR thermometry prompt us to design an MR compatible hyperthermia applicator: the MRcollar. In this work, we validate the design, numerical model, and MR performance of the MRcollar. The MRcollar antennas have low reflection coefficients $(<-15 \mathrm{~dB})$ and the intended low interaction between the individual antenna modules $(<-32 \mathrm{~dB})$. A $10{ }^{\circ} \mathrm{C}$ increase in 3 min was reached in a muscle-equivalent phantom, such that the specifications from the European Society for Hyperthermic Oncology were easily reached. The MRcollar had a minimal effect on MR image quality and a five-fold improvement in SNR was achieved using the integrated coils of the MRcollar, compared to the body coil. The feasibility of using the MRcollar in an MR environment was shown by a synchronous heating experiment. The match between the predicted SAR and measured SAR using MR thermometry satisfied the gamma criteria [distance-to-agreement $=5 \mathrm{~mm}$, dose-difference $=7 \%$ ] All experiments combined show that the MRcollar delivers on the needs for MR-hyperthermia in the H\&N and is ready for in vivo investigation.

Keywords: hyperthermia; microwave hyperthermia; MR thermometry; MRI guided interventions

\section{Introduction}

Clinical studies have shown that hyperthermia increases the effectiveness of radiotherapy and chemotherapy for various anatomical sites, without inducing significant side effects [1-4]. This adjuvant effect of hyperthermia on radiotherapy was shown also for 
cancers of the head and neck (H\&N) [5-9]. In 2007, we developed the HYPERcollar [10] in order to extend the application of hyperthermia from superficial regions to deeper target regions. This device was improved and replaced by the HYPERcollar3D in 2014 [11,12]. These devices were specifically developed for conformal heating of large target regions ranging from 4 to $15 \mathrm{~cm}$ of an advanced $H \& N$ disease [13]. Placement of invasive temperature catheters in the $\mathrm{H} \& \mathrm{~N}$ region is challenging, and intrinsically provides temperature information from only a limited number of discrete measurement points. Non-invasive temperature monitoring by magnetic resonance thermometry (MRT) has shown clinical potential for obtaining detailed 3D temperature maps from the region of interest [14]. Based on our extensive clinical experience with model-based design from the development of the HYPERcollar and HYPERcollar3D, we have designed the world's-first magnetic resonance (MR) compatible microwave hyperthermia applicator for the H\&N: the MRcollar [15]. This novel design is based on a radically new antenna element and array concept. However, it still requires validation of the heating characteristics and MR compatibility before its introduction for studies in volunteers and patients.

A series of dedicated verification measurements of the heating pattern are recommended before introducing a hyperthermia device in clinical practice [16-18]. These verification measurements are aimed at improving the translation of hyperthermia treatment planning (HTP) settings into the clinical routine. While quality assurance measurements make HTP a more reliable tool to ensure target conformal electromagnetic field energy delivery, the uncertainties in tissue electromagnetic and thermal properties affect the reliability of the model based predicted temperatures [19-21]. Hence, detailed temperature measurements, both in the target region and healthy tissues, are required to assess the true temperatures achieved and to enable dynamic adaptation of the power distribution for maximizing the applied thermal dose. Non-invasive 3D temperature monitoring during the hyperthermia is therefore needed for exploiting the focusing potential and for delivering the optimal thermal dose and hence achieving the full clinical potential of hyperthermia.

Literature indicates that the proton resonance frequency shift method, i.e., the most common MRT method, can provide 3D temperature maps with around $0.5^{\circ} \mathrm{C}$ accuracy [22-24]. For H\&N hyperthermia, several studies [25-27] have shown the feasibility of adopting MR compatible applicators; however, to date, none of them has been adopted in clinical practice. Recently, we presented the novel MR compatible applicator for the H\&N region: the MRcollar [15] equipped with a novel dual-function applicator concept [28,29]. In this design, novel MR-transparent Yagi-Uda antennas [30] were combined with dielectric reflector modules (DiPRA) to minimize radiofrequency (RF) radiation towards adjacent antenna elements and towards the RF coil of the MR scanner and to minimize the water bolus volume. Furthermore, this new applicator design uses the dual-function applicator concept. These innovative approaches aim to improve the hyperthermia dose delivery, handling of the hyperthermia device, and enable and improve MRI for hyperthermia treatment monitoring. Still, the applicator manufactured based on this design needs to be validated before its introduction in clinical practice.

The aim of this study was to validate the MRcollar design and the numerical model, as well as to validate in MR environment under the light of Medical Devices Directive 93/42/EEC. First, the electromagnetic design of the antennas and the array was validated by reflection and cross-coupling measurements. Second, the achievable heating rate of the device was measured using optical fiber temperature probes inserted into a cylindrical phantom. Third, focus steering capabilities were measured in a muscle-equivalent cylindrical split-phantom by an infrared (IR) camera. Next, the MR imaging performance of the integrated MRcollar coils were compared to the body coil of the MR scanner by measuring Signal-to-noise Ratio (SNR). Lastly, the feasibility of the heating and treatment monitoring in the MR environment were tested. These steps allowed us to experimentally verify the feasibility of using the prototype MRcollar design for MR guided hyperthermia. 


\section{Materials and Methods}

\subsection{The MRcollar Design}

The MRcollar (Figure 1) consists of two crescent moon-shaped shells each consisting of six antenna modules in a $2 \times 3$ arrangement placed around the H\&N for 12 antenna setup. Every module contains a printed Yagi-Uda antenna submerged in water and operating at 433.92 MHz. A water bolus, i.e., a "bag" of flexible foil filled with demineralized water, is placed between the antenna modules and the patient surface in order to improve coupling of electromagnetic waves and to prevent unwanted heating of patient's skin. The MRcollar position can be freely adjusted in all three directions. Furthermore, it can be rotated along the $\mathrm{z}$-axis (sagittal plane) to $15^{\circ}$, which is the preferred applicator position for the tumors in the larynx region. The base plate was designed to fit into the dedicated slot on the MR patient bed.

The MRcollar houses 8-channel MR receiver coil array tuned to $63.89 \mathrm{MHz}$ for MR imaging at $1.5 \mathrm{~T}$. Each of the moon-shaped shells include a 3-channel receive coil array (a bottom $(15 \times 8 \mathrm{~cm})$, a central $(15 \times 12 \mathrm{~cm})$ and a top $(15 \times 8 \mathrm{~cm})$ rectangular shaped loops) and the head rest includes a 2-channel receive coil array (butterfly coil $20 \times 9 \mathrm{~cm}$ and $9 \times 9 \mathrm{~cm}$ rectangular shaped loops) [29]. The coils are fabricated using etched copper wire. To minimize the coupling between the neighbouring elements, geometric decoupling was used. Decoupling from the transmit coil has been achieved by a passive and active diode detuning circuit.

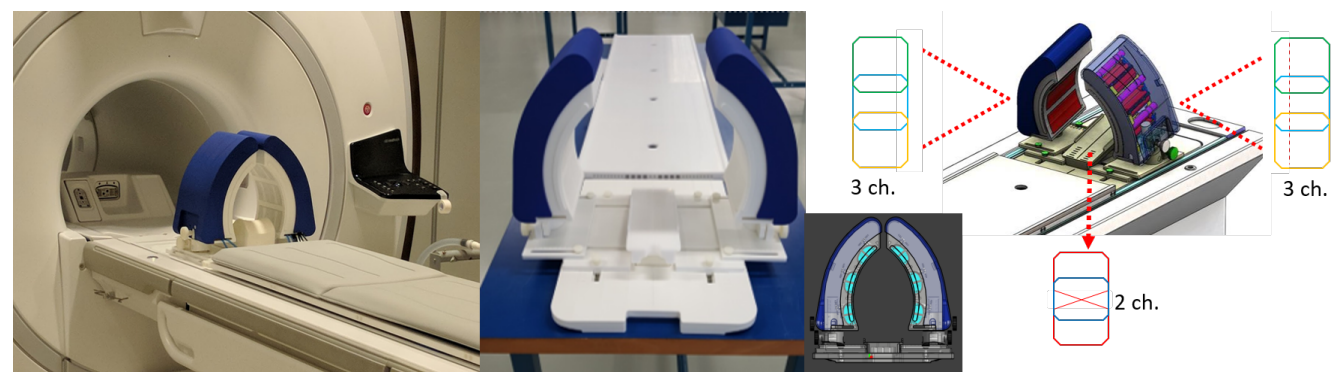

Figure 1. Picture of MRcollar applicator prototype without the inner water bolus and the location of the integrated MR receiver arrays.

\subsection{Phantoms}

Two cylindrical "split" phantoms (shown in Figure 2a) were made and filled with muscle-equivalent material consisting of deionized water, agar, sodium chloride, polyethylene powder and TX-151 (electrical conductivity $0.39 \mathrm{~S} / \mathrm{m}$, relative permittivity 59, thermal conductivity $0.6 \mathrm{~W} / \mathrm{m} /{ }^{\circ} \mathrm{C}$, specific heat capacity $3800 \mathrm{~W} / \mathrm{kg} /{ }^{\circ} \mathrm{C}$ ). Dielectric properties of the phantoms were measured using a dielectric assessment kit (DAK-4, Speag, Zurich, Switzerland). Thermal properties of the phantoms were measured using a thermal property analyzer (TEMPOS, METER Group, Inc., Pullman, WA, USA). The cylindrical phantom (T1: 108 ms, T2: 96 ms; shown in Figure 2b) was provided by the MR vendor (General Electric Health Care, Waukesha, WI, USA). 

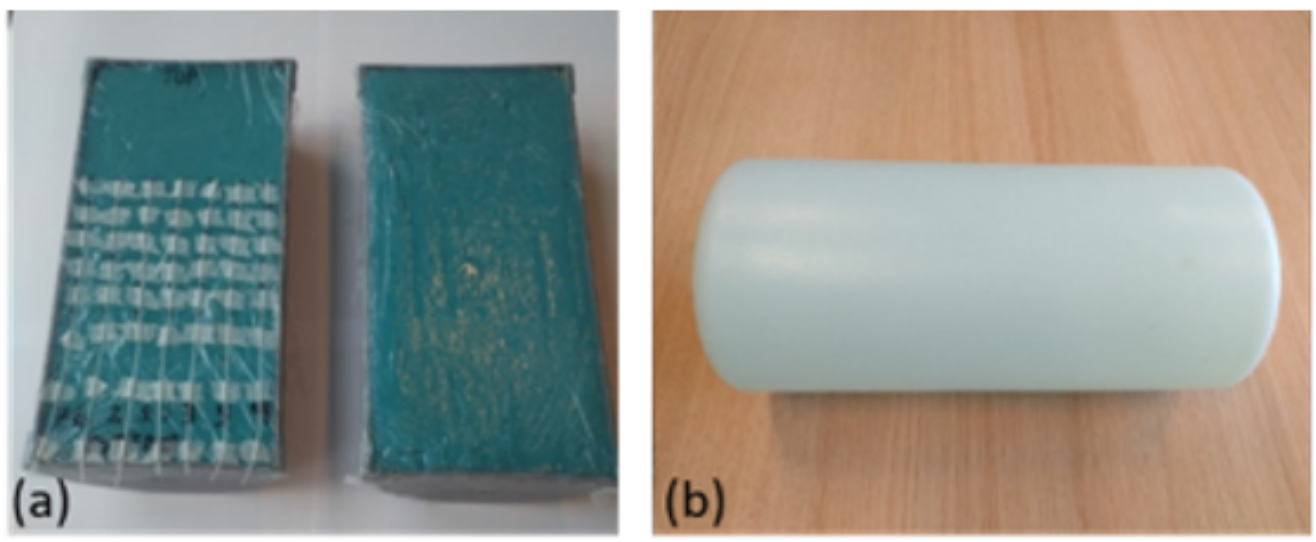

Figure 2. Phantoms (a) Cylindrical Split Phantom (b) Cylindrical MR phantom.

\subsection{Antenna Characterization Measurements, Heating and Focusing Steering Capabilities}

We measured the S-matrix of the hyperthermia array by attaching a network vector analyzer (ZNC 3, Rhode \& Schwarz, Munich, Germany) to the antennas using the cylindrical split phantom as a load.

For the heating characterization measurements, the split phantom was used. MR images of the setup consisting of applicator, water bolus and phantom were acquired before the heating experiment to correctly capture specifically the irregular shape of the water bolus. Then the images were manually segmented using iSeg (v3.10 Zurich MedTech, Zurich, Switzerland). The segmented models of the phantom and the water bolus were manually overlaid with the MRcollar numerical model. Electromagnetic field distributions were computed per antenna channel using Sim4Life (v.4.4.1.3808, Zurich MedTech, Zurich, Switzerland). A $433.92 \mathrm{MHz}$ excitation harmonic signal was applied for 20 periods to each antenna. The size of the calculation domain was 43 million voxels, with a maximum voxel size of $1.5 \times 1.5 \times 1.5 \mathrm{~mm}^{3}$, refined to $0.5 \times 0.5 \times 0.5 \mathrm{~mm}^{3}$ for the antenna sources. Three heat focus locations were selected, i.e., central focus $(0,0,0) \mathrm{mm}$, x-steered $(20,0,0)$ $\mathrm{mm}$, z-steered $(0,0,40) \mathrm{mm}$, and the corresponding amplitude and phase per channel were calculated using Time-reversal method [31].

The heating experiments were performed by heating the phantom for $180 \mathrm{~s}$ with total input power of $180 \mathrm{~W}$. Temperature was monitored during the heating process by 27 fiber optic temperature probes (FISO FOT-NS-577E, Fiso, Quebec, QC, Canada). Specific absorption rate (SAR) was then calculated by the temperature increase in the first $60 \mathrm{~s}$. The temperature distribution of the split phantom was imaged with an IR camera before the heating and quickly ( $\approx 10 \mathrm{~s}$ after the power was turned off) after opening both halves, after the heating session. The SAR distributions were calculated using the temperature rise method. First, the temperature increase was calculated using the before and after heating IR images. Second, the temperature increase was scaled by the ratio of specific heat ratio of the phantom and the total heating duration to calculate the SAR. Heating focus-size was defined as the length and the width of the 50\% iso-SAR contour. The measurements were repeated with an identical phantom. Forwarded amplitude and phase, as well as reflected power, were continuously monitored using the clinical measurement setup [32].

We quantified the match between the measurements and the numerical model using the Gamma-method [33]. We have defined two sets of tolerances: criteria (1) dose difference $10 \%$ and distance to agreement $10 \mathrm{~mm}$ (gamma10); criteria (2) dose difference 5\% and distance to agreement $5 \mathrm{~mm}$ (gamma5). The analysis was done using all voxels absorbing at least $30 \%$ of the maximum measured SAR in the phantom, to exclude the voxels heated due to thermal conduction.

\subsection{MR-Compatibility Measurements}

The cylindrical phantom was used to evaluate and compare the SNR acquired with the integrated MRcollar coils and the body coil of a $1.5 \mathrm{~T}$ MR $450 \mathrm{~W}$ scanner (General 
Electric Health Care, Waukesha, WI, USA). The region where the SNR is calculated shown with a red circle in Figure 5.The evaluation for SNR was done using a fast gradient echo sequence with the following parameters: repetition time $100 \mathrm{~ms}$, echo time $19.2 \mathrm{~ms}$, flip angle $30^{\circ}$, number of slices 1 , resolution: $1.25 \times 1.25 \times 3 \mathrm{~mm}^{3}$, matrix resolution $256 \times 256$, bandwidth $31.2 \mathrm{kHz}$, number of excitations 1, total acquisition time $25.6 \mathrm{~s}$. SNR was calculated using the dual image subtraction method [34].

The feasibility of using the MRcollar in the MRI environment was tested in a synchronous heating experiment. The cylindrical split phantom was heated for $480 \mathrm{~s}$ with total input power of 180 W. Each antenna was excited with equal amplitude and phase. The MRT was calculated using the proton resonance frequency shift method [35]. Images were acquired using a fast gradient echo sequence with the following parameters: repetition time $68 \mathrm{~ms}$, echo time $13.2 \mathrm{~ms}$, flip angle $55^{\circ}$, number of slices 3, resolution: $2.5 \times 2.5 \times 5 \mathrm{~mm}^{3}$, matrix resolution $128 \times 128$, bandwidth $31.2 \mathrm{kHz}$, number of excitations, total acquisition time $8.7 \mathrm{~s}$. Approximately $2 \mathrm{~min}$ after the heating had been stopped, the split phantom was imaged with an IR camera to validate the MRT results. The MRT slice is $2.5 \mathrm{~cm}$ deeper than the split phantom surface where the IR camera measurements were taken.

In Table 1, summary of the measurements which are done for the validation study are given.

Table 1. Summary of the measurements.

\begin{tabular}{|c|c|c|}
\hline Topic & Phantom & Measurement Method \\
\hline $\begin{array}{c}\text { Antenna } \\
\text { characterization }\end{array}$ & $\begin{array}{l}\text { Cylindrical } \\
\text { Split Phantom }\end{array}$ & $\begin{array}{l}\text { Antenna reflection }\left(S_{i i}\right) \text { and cross coup- } \\
\text { ling }\left(S_{i j}\right) \text { measurements by the VNA. }\end{array}$ \\
\hline \multicolumn{3}{|l|}{ Heating ability } \\
\hline $\mathrm{SAR}_{\max }$ & $\begin{array}{l}\text { Cylindrical } \\
\text { Split Phantom }\end{array}$ & $\begin{array}{l}\text { Maximum temperature increase in the } \\
\text { first } 60 \mathrm{~s} \text { measured by the } \\
\text { fiber optic probes and scaled using the } \\
\text { specific heat capacity of the phantom as } \\
\text { well as heating duration. }\end{array}$ \\
\hline $\begin{array}{l}\text { Focus Size } \\
\text { and steering }\end{array}$ & $\begin{array}{l}\text { Cylindrical } \\
\text { Split Phantom }\end{array}$ & $\begin{array}{l}\text { Differential temperature maps from } \\
\text { an IR camera before and after } 180 \mathrm{~s} \\
\text { of heating. Focus size was } \\
\text { defined as length and width of the } \\
50 \% \text { iso-SAR contour. This experiment } \\
\text { was repeated for three different focus } \\
\text { locations with two identical phantoms. }\end{array}$ \\
\hline \multicolumn{3}{|l|}{ MR compatibility } \\
\hline MR SNR & $\begin{array}{l}\text { Cylindrical } \\
\text { Phantom }\end{array}$ & $\begin{array}{l}\text { The dual image subtraction method was } \\
\text { performed using a fast gradient echo } \\
\text { sequence. }\end{array}$ \\
\hline Heating in MRI & $\begin{array}{l}\text { Cylindrical } \\
\text { Split Phantom }\end{array}$ & $\begin{array}{l}\text { MR images were acquired before and } \\
\text { after the } 480 \text { s of heating window. } \\
\text { Temperature change calculated by } \\
\text { PRFS method. }\end{array}$ \\
\hline
\end{tabular}

\section{Results}

\subsection{Reflection and Cross-Coupling Measurements}

The complete S-matrix of the MRcollar system is shown in Figure 3. The primary reflection coefficient $\left(\mathrm{S}_{i i}\right)$ of all antennas was on average below the design goal of $-15 \mathrm{~dB}$ (mean \pm standard deviation $=-17 \pm 6 \mathrm{~dB}$, worst $-11 \mathrm{~dB}$ ) and the cross-coupling between the antennas $\left(\mathrm{S}_{i j}\right)$ was $<-20 \mathrm{~dB}$ for all except four combinations (mean \pm standard deviation $=-32 \pm 7 \mathrm{~dB}$, worst $-11 \mathrm{~dB}$ ). 


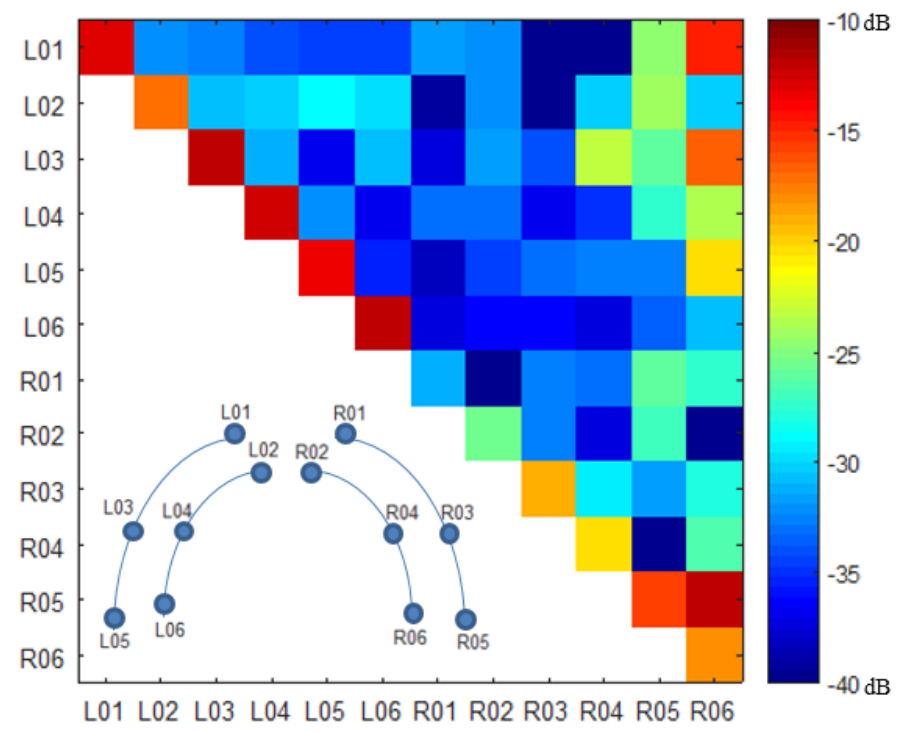

Figure 3. S-matrix and a schematic showing the antenna locations using fish-eye perspective for clarity.

\subsection{Heating, Steering Capabilities and Focus-Size}

Using $180 \mathrm{~W}$ total input power for $180 \mathrm{~s}$, a $10.3 \pm 0.19^{\circ} \mathrm{C}$ temperature increase was achieved for all three optimization settings. The maximum measured SAR was 240 and $235 \mathrm{~W} / \mathrm{kg}$ for central steering, 224 and $221 \mathrm{~W} / \mathrm{kg}$ for $\mathrm{x}$-steering, and 224 and $227 \mathrm{~W} / \mathrm{kg}$ for z-steering. The heating patterns for these three different focus locations are shown in Figure 4 . The length and width of the focus was 82 and $30 \mathrm{~mm}$ for central steering, 85 and $32 \mathrm{~mm}$ for z-steering, and 83 and $33 \mathrm{~mm}$ for x-steering. The overall results for the gamma analysis is given in Table 2. Gamma10 was full-filled by $88 \%$ of the voxels for central steering, $98 \%$ for z-steering, and $99 \%$ for $x$-steering. Gamma 5 was fulfilled by $72 \%$ of the voxels for central steering, $74 \%$ for $z$-steering, and $79 \%$ for $x$-steering.

Table 2. Results of the gamma analysis.

\begin{tabular}{ccc}
\hline Variable & Gamma10 & Gamma5 \\
\hline Central Focus & $88 \%$ & $72 \%$ \\
X-steering & $98 \%$ & $74 \%$ \\
Z-steering & $99 \%$ & $79 \%$ \\
MRT & $99 \%$ & $92 \%$ \\
\hline
\end{tabular}

\subsection{MR-Compatibility Measurements}

Figure 5 shows example magnitude images acquired with the body coil and the MRcollar 8-channel receive coil array. The location of the printed antennas are visible as black lines in the DiPRA modules which are filled with demineralized water. Further local MRI distortions are visible in the vicinity of the antennas which are caused by the metallic parts of these printed antenna elements and the connectors. The signal void in the left water bolus is caused by the support structure which is doped with the iron oxide nanoparticles. SNR was 23 for imaging using the body-coil and SNR was improved around five-fold to 120 for the 8-channel coil of the MRcollar. 

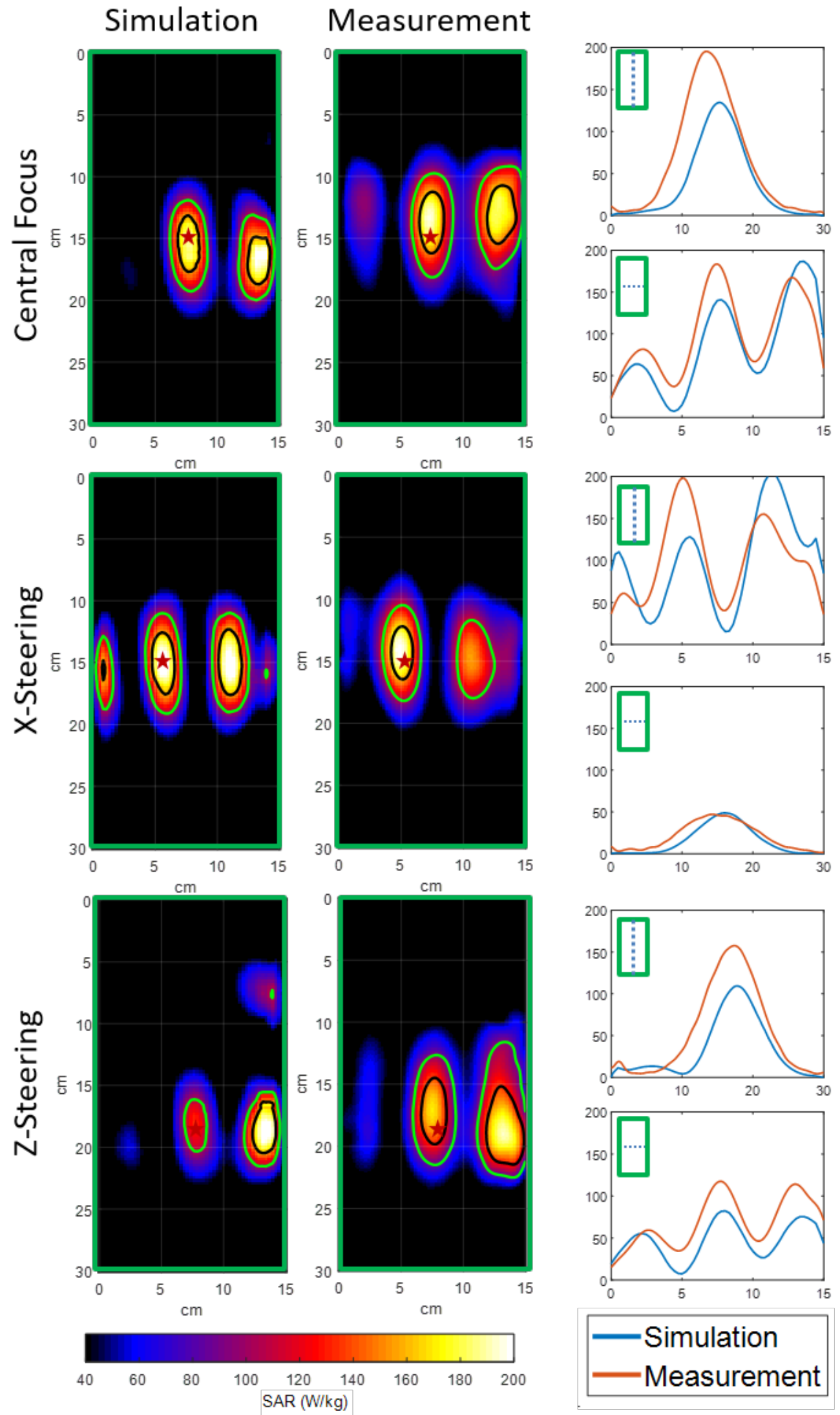

Figure 4. Simulated and measured SAR distributions (left and middle) and line plot along the phantom's vertical and the horizontal axis. The green border shows the phantom outline and the red star shows the approximated focus point: central (top), $x=+2 \mathrm{~cm}$ (middle) and $\mathrm{z}=+4 \mathrm{~cm}$ (bottom). 
a)

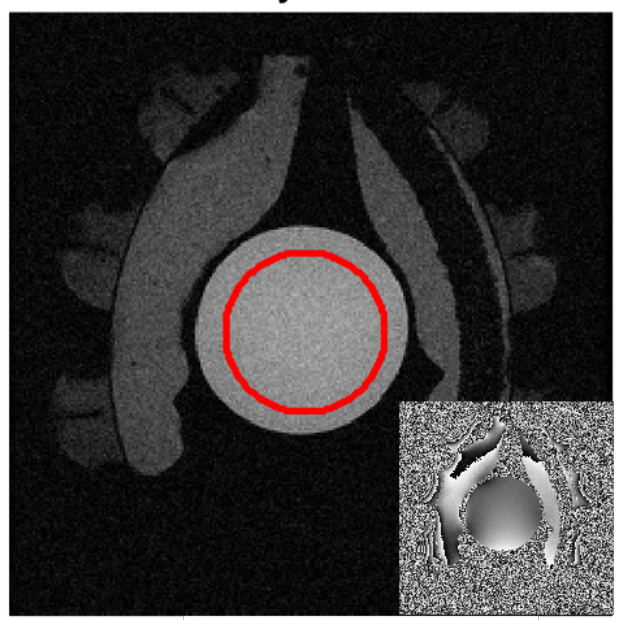

c)

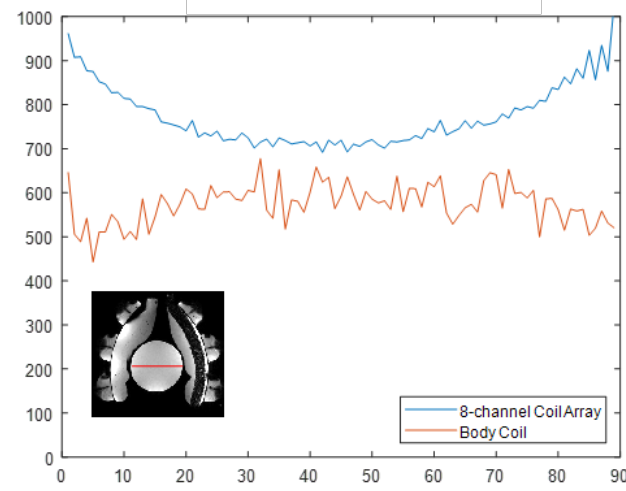

b) 8-channel Coil Array

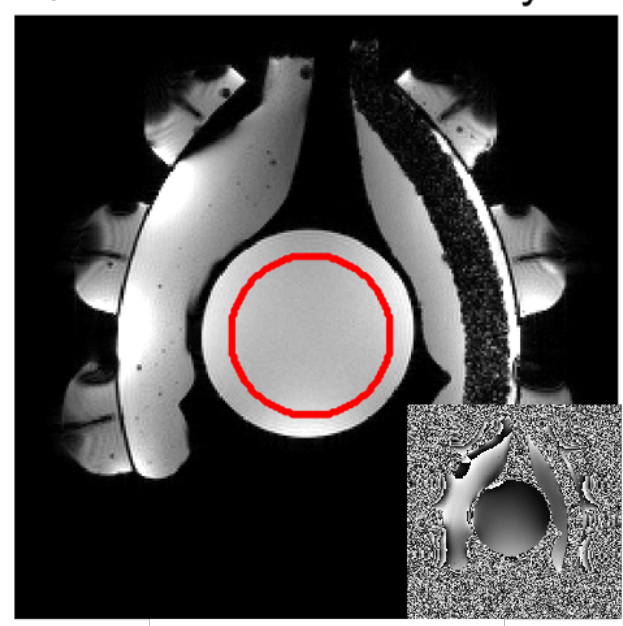

d) Along y-axis

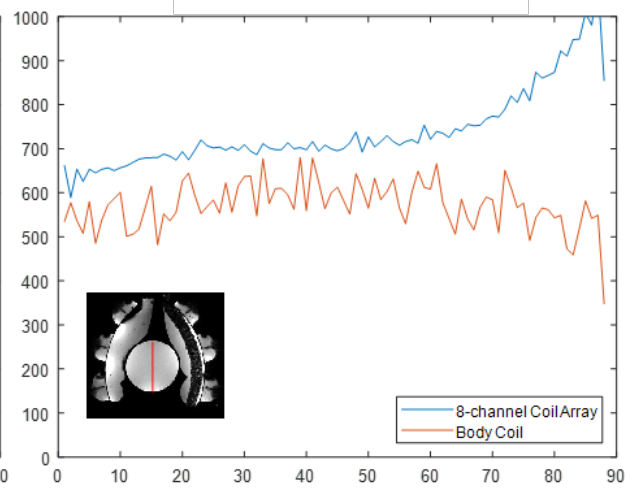

Figure 5. MR magnitude and phase images acquired with (a) MR scanner's body coil (b) 8-channel coil array of the MRcollar. The red circle highlights the region of interest where SNR was calculated. Line plots of signal intensities along (c) x-axis (d) y-axis acquired with the 8-channel coil array (blue) and the body coil (orange).

In Figure 6, the predicted temperature increase (Figure 6a) and measured temperatures (PRFS method: Figure 6b; IR camera: Figure 6c) are shown. The PRFS measurement has a good match with both prediction and IR measurements, showing that the heating ability of the MRcollar is not affected by the MRI environment. Note that the pattern is more spread in the IR measurements due to conduction during the time needed to open the two halves and perform the IR measurement. The gamma match between the prediction and MRT measurements were fulfilled by $99 \%$ of the voxels for the gamma10. Gamma5 was passed by $92 \%$ of the voxels which does not satisfy the acceptance criteria (95\%). The gamma match between the SAR predicted and measured using MR thermometry was satisfied for [distance-to-agreement $=5 \mathrm{~mm}$, dose-difference $=7 \%$ ]. 


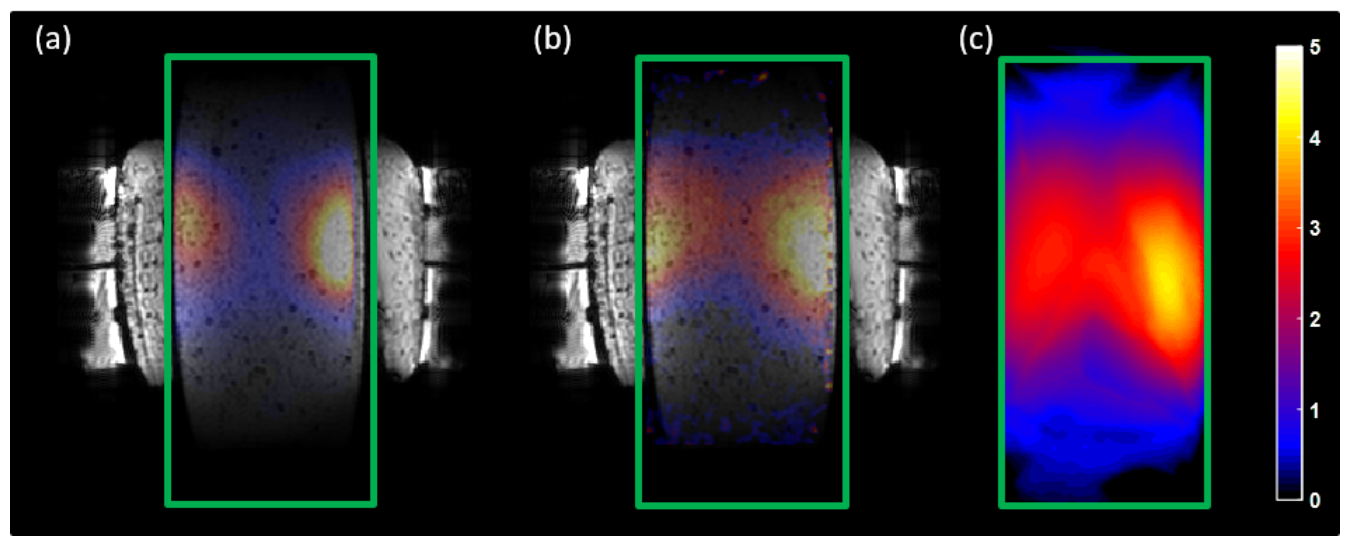

Figure 6. Simulated and measured temperature distributions (a) Simulated temperature increase image (b) Measured temperature increase with MRT (c) Measured temperature increase with IR camera. The green rectangle shows the borders of the phantom.

\section{Discussion}

In this study, we experimentally validated the MRcollar prototype and its numerical model. Antenna loss and inter element cross coupling measurements demonstrated the well matched operation and the very low coupling predicted by earlier simulations [15]. The heating performance predicted by the simulations was validated using the Gammamethod in three phantom experiments. Our results also demonstrate the feasibility and benefit of equipping the MRcollar with receive coils: this greatly improved SNR compared to signal acquisition with the body coil of the MR scanner. The feasibility of using the MRcollar in the MRI environment and the potential of MRT was shown in a synchronous heating experiment. Our results show that hyperthermia treatment in an MR scanner is feasible with the presence of the MRcollar within the MR scanner bore.

\subsection{EM Compatibility}

The DiPRA modules satisfy the original reflection characteristic requirements set for the original single Yagi-Uda antenna by Paulides et al. [30] $\left(\mathrm{S}_{11}<-15 \mathrm{~dB}\right)$ on average. The measured cross coupling between the DiPRA modules showed overall good performance $\left(\mathrm{S}_{12}<-32 \pm 7 \mathrm{~dB}\right)$ and matched the predicted performance by simulations $\left(\mathrm{S}_{12}=-27 \mathrm{~dB}[15]\right)$.

\subsection{Heating Capabilities}

The capabilities of the MRcollar prototype to focus and steer the heating pattern were tested using the same tests as those used for the HYPERcollar in Paulides et al. [36]. However, we used the time reversal focusing technique [31] to determine the phase and amplitude coefficients driving the applicator to adjust to the patient conformal shape of the MRcollar prototype and achieve the desired focusing. The measured focus size in the three different configurations (length $83 \mathrm{~mm}$, width $31 \mathrm{~mm}$ ), is in agreement with the focus size of the HYPERcollar (length 87-112 mm, width $35 \mathrm{~mm}$ in [36]) and other applicators operating at $434 \mathrm{MHz}[37,38]$. The use of the time reversal technique indeed resulted in central and steered foci (with secondary hotspots) so we did not need a more sophisticated optimization approach [39-44], which would intrinsically require a target volume and constraints and only blur the focusing in this first validation step. The secondary hotspots which are the product of the time reversal optimization, can be suppressed with addition of constraints to the optimization function.

In the absence of temperature rise criteria for deep hyperthermia applicators, we used those defined in the recent quality assurance document for superficial hyperthermia applicators: at least a $6^{\circ} \mathrm{C}$ temperature increase in a maximum of $6 \mathrm{~min}$ [17]. The MRcollar fulfilled the above criteria in less than two minutes, i.e., around $70 \%$ less than prescribed. Moreover, the total input power used in this study was only $10 \%$ of the available power of 
the clinical amplifiers. Note, however, that the head and neck region is prone to a very high thermoregulation and that smaller heat foci require more energy [45]. Therefore, validation of the true heating capabilities of the MRcollar in patients is still unknown.

The gamma analysis resulted in a good match between the predicted and experimentally measured SAR patterns for all three different focus settings, i.e., $88-99 \%$ for gamma10 while they were not satisfactory for gamma5, i.e., $72-79 \%$. In all three cases, the discrepancies were near the edges of the phantom and therefore far from the focus region. The differences can be explained by changes in the shape of the water bag between the experimental setup and the simulated shape. The good match achieved between the predictions and the MRT measurements (99\% for gamma10 and $92 \%$ for gamma5) also shows that accurate reconstruction of the setup is mandatory to satisfy strict quality assurance criteria. Furthermore, the difficulty in registration of the measurements between the IR camera and the simulations further amplifies the mismatch.

\subsection{MR Compatibility}

Our MR compatibility measurements of the MRcollar show that the metallic parts contained in the antenna structures have a minimal effect on image quality in the phantoms, i.e., the clinically relevant part of the field of view. The susceptibility artefacts induced by the metallic parts were contained in the antenna cavities. Integrating the receiver coils in the MRcollar led to the an important improvement in SNR. The 5-fold increase in the SNR can potentially improve the accuracy and the precision of the MRT results since MRT is a differential measurement method which amplifies the effect of the noise. In addition to the SNR benefits, the integrated coil-array also allows for the use of advanced MR techniques, such as parallel imaging, to enable faster acquisition times (from $8.7 \mathrm{~s}$ in this study to $2-4$ s) for correction of the impact of respiratory motion. Earlier, we showed that a further increase in SNR and acquisition speed can be achieved by using iron oxide nanoparticles in the water bolus to enable reducing the imaging field of view [46]. All benefits combined can further help the adoption of MR-guided hyperthermia treatments and pave the way for wider acceptance in the clinic.

The heating experiments in the MRI environment proved the feasibility of the dualfunction applicator concept. The temperature increase was successfully monitored using the PRFS method and the shape of the predicted and measured temperature increases matched well at the main and secondary hotspots. The near perfect match $(99 \%)$ was achieved for gamma10 and the result for gamma5 is highly satisfactory $(92 \%)$. These results also reflect the fact that MR compatibility of a hyperthermia applicator also benefits from having better quality assurance tools. Furthermore, during the treatment, MRI can provide feedback on the patient positioning in addition to the temperature change. The discrepancy in the measured maximum temperature increase between the PRFS and IR camera image can be explained by the two main differences. The IR camera image was taken two minutes after the heating was stopped while the MRT image was acquired as soon as possible. Another issue is that, the visualized slice for the IR camera (center of the split phantom) and the MRT slice $(2.5 \mathrm{~cm}$ deep from the center) are different.

\section{Conclusions}

In this study, we introduced the MRcollar; the world's-first MR compatible microwave hyperthermia applicator for the head and neck; and validated its design and operation. Antenna characteristics were measured satisfactorily and the heating rate requirements set by ESHO were satisfied. The measurements and the predicted distributions had a good agreement; satisfying the minimum acceptance criteria set by gamma10. The effect of the metallic structures of the MRcollar on the MRI contained in the local vicinity. The MRcollar receive coils improved the SNR by five-fold, compared to the body coil of the MR scanner. Operation in the MRI environment was shown feasible, and the measured temperature increase distributions matched well to PRFS and IR camera measurements. The conducted 
experiments on phantoms show that the MRcollar satisfy the requirements for heating and imaging. The MRcollar is now ready for in vivo investigations in the H\&N.

Author Contributions: Conceptualization, K.S., T.D. and M.M.P.; methodology, K.S., T.D., G.G.B., and M.M.P.; software, K.S. and T.D.; validation, K.S. and G.G.B.; formal analysis, K.S.; investigation, K.S. and G.G.B.; resources, J.A.H.-T., G.C.v.R. and M.M.P.; data curation, K.S.; writing-original draft preparation, K.S.; writing—review and editing, K.S., T.D., G.G.B., J.A.H.-T., G.C.v.R. and M.M.P.; visualization, K.S.; supervision, J.A.H.-T., G.C.v.R. and M.M.P.; project administration, K.S., G.G.B. and M.M.P.; funding acquisition, J.A.H.-T., G.C.v.R. and M.M.P. All authors have read and agreed to the published version of the manuscript.

Funding: This work was developed within the framework of COST Action MyWAVE CA17115 and it was funded by the Dutch Cancer Society grants EMCR 2012-5472 and 11368.

Institutional Review Board Statement: Not applicable.

Informed Consent Statement: Not applicable.

Data Availability Statement: The data presented in this study are available on request from the corresponding author.

Conflicts of Interest: G.C.v.R. and M.M.P. have financial interest in Sensius BV.

\section{References}

1. Datta, N.R.; Puric, E.; Klingbiel, D.; Gomez, S.; Bodis, S. Hyperthermia and radiation therapy in locoregional recurrent breast cancers: A systematic review and meta-analysis. Int. J. Radiat. Oncol. Biol. Phys. 2016, 94, 1073-1087. [CrossRef]

2. Datta, N.R.; Rogers, S.; Ordóñez, S.G.; Puric, E.; Bodis, S. Hyperthermia and radiotherapy in the management of head and neck cancers: A systematic review and meta-analysis. Int. J. Hyperth. 2016, 32, 31-40. [CrossRef] [PubMed]

3. Datta, N.R.; Rogers, S.; Klingbiel, D.; Gómez, S.; Puric, E.; Bodis, S. Hyperthermia and radiotherapy with or without chemotherapy in locally advanced cervical cancer: A systematic review with conventional and network meta-analyses. Int. J. Hyperth. 2016, 32, 809-821. [CrossRef] [PubMed]

4. Bakker, A.; van der Zee, J.; van Tienhoven, G.; Kok, H.P.; Rasch, C.R.; Crezee, H. Temperature and thermal dose during radiotherapy and hyperthermia for recurrent breast cancer are related to clinical outcome and thermal toxicity: A systematic review. Int. J. Hyperth. 2019, 36, 1023-1038. [CrossRef]

5. Amichetti, M.; Romano, M.; Busana, L.; Bolner, A.; Fellin, G.; Pani, G.; Tomio, L.; Valdagni, R. Hyperfractionated radiation in combination with local hyperthermia in the treatment of advanced squamous cell carcinoma of the head and neck: A phase I-II study. Radiother. Oncol. 1997, 45, 155-158. [CrossRef]

6. Hua, Y.; Ma, S.; Fu, Z.; Hu, Q.; Wang, L.E.I.; Piao, Y. Intracavity hyperthermia in nasopharyngeal cancer: A phase III clinical study. Int. J. Hyperth. 2011, 27, 180-186. [CrossRef] [PubMed]

7. Verduijn, G.M.; de Wee, E.M.; Rijnen, Z.; Togni, P.; Hardillo, J.A.U.; Ten Hove, I.; Franckena, M.; van Rhoon, G.C.; Paulides, M.M. Deep hyperthermia with the HYPERcollar system combined with irradiation for advanced head and neck carcinoma-A feasibility study. Int. J. Hyperth. 2018, 34, 994-1001. [CrossRef]

8. Feasibility, SAR Distribution and Clinical Outcome upon Re-Irradiation and Deep Hyperthermia Using the Hypercollar3D in Head and Neck Cancer Patients. Submitt. Cancers. 2021. Available online: https://programm.conventus.de/index. php?id=icho2021\&tx_coprogramm_programm\%5Bprogramm\%5D=106\&tx_coprogramm_programm\%5Bsession \%5D=14\&tx_ coprogramm_programm\%5BcurrentPage\%5D=\&tx_coprogramm_programm\%5Baction\%5D=programm\&tx_coprogramm_ programm\%5Bcontroller\%5D=Source\&cHash=861da91e121ea43a7bf09765137e7589 (accessed on 28 September 2021).

9. Zschaeck, S.; Weingärtner, J.; Ghadjar, P.; Wust, P.; Mehrhof, F.; Kalinauskaite, G.; Ehrhardt, V.H.; Hartmann, V.; Tinhofer, I.; Heiland, M.; et al. Fever range whole body hyperthermia for re-irradiation of head and neck squamous cell carcinomas: Final results of a prospective study. Oral Oncol. 2021, 116, 105240. [CrossRef]

10. Paulides, M.; Bakker, J.; Neufeld, E.; van der Zee, J.; Jansen, P.; Levendag, P.; van Rhoon, G. The HYPERcollar: a novel applicator for hyperthermia in the head and neck Int. J. Hyperth. 2007, 23, 567-576. [CrossRef]

11. Togni, P.; Rijnen, Z.; Numan, W.C.M.; Verhaart, R.F.; Bakker, J.F.; Van Rhoon, G.C.; Paulides, M.M. Electromagnetic redesign of the HYPERcollar applicator: Toward improved deep local head-and-neck hyperthermia. Phys. Med. Biol. 2013, 58, 5997. [CrossRef]

12. Rijnen, Z.; Togni, P.; Roskam, R.; van de Geer, S.G.; Goossens, R.H.M.; Paulides, M.M. Quality and comfort in head and neck hyperthermia: A redesign according to clinical experience and simulation studies. Int. J. Hyperth. 2015, 31, 823-830. [CrossRef] [PubMed]

13. Paulides, M.M.; Verduijn, G.M.; Van Holthe, N. Status quo and directions in deep head and neck hyperthermia. Radiat. Oncol. 2016, 11, 21. [CrossRef] [PubMed]

14. Winter, L.; Oberacker, E.; Paul, K.; Ji, Y.; Oezerdem, C.; Ghadjar, P.; Thieme, A.; Budach, V.; Wust, P.; Niendorf, T. Magnetic resonance thermometry: Methodology, pitfalls and practical solutions. Int. J. Hyperth. 2016, 32, 63-75. [CrossRef] 
15. Drizdal, T.; Sumser, K.; Bellizzi, G.G.; Fiser, O.; Vrba, J.; Rhoon, G.C.V.; Yeo, D.T.B.; Paulides, M.M. Simulation guided design of the MRcollar: A MR compatible applicator for deep heating in the head and neck region. Int. J. Hyperth. 2021, 38, 382-392. [CrossRef] [PubMed]

16. Bruggmoser, G.; Bauchowitz, S.; Canters, R.; Crezee, H.; Ehmann, M.; Gellermann, J.; Lamprecht, U.; Lomax, N.; Messmer, M.B.; Ott, O.; et al. Quality assurance for clinical studies in regional deep hyperthermia. Strahlenther. Onkol. 2011, 187, 605. [CrossRef] [PubMed]

17. Trefná, H.D.; Crezee, J.; Schmidt, M.; Marder, D.; Lamprecht, U.; Ehmann, M.; Nadobny, J.; Hartmann, J.; Lomax, N.; AbdelRahman, S.; et al. Quality assurance guidelines for superficial hyperthermia clinical trials. Strahlenther. Onkol. 2017, 193, 351-366. [CrossRef]

18. Dobšíček Trefná, H.; Schmidt, M.; Van Rhoon, G.; Kok, H.; Gordeyev, S.; Lamprecht, U.; Marder, D.; Nadobny, J.; Ghadjar, P.; Abdel-Rahman, S.; et al. Quality assurance guidelines for interstitial hyperthermia. Int. J. Hyperth. 2019, 36, 276-293. [CrossRef]

19. Verhaart, R.F.; Verduijn, G.M.; Fortunati, V.; Rijnen, Z.; van Walsum, T.; Veenland, J.F.; Paulides, M.M. Accurate 3D temperature dosimetry during hyperthermia therapy by combining invasive measurements and patient-specific simulations. Int. J. Hyperth. 2015, 31, 686-692. [CrossRef]

20. Aklan, B.; Zilles, B.; Paprottka, P.; Manz, K.; Pfirrmann, M.; Santl, M.; Abdel-Rahman, S.; Lindner, L. Regional deep hyperthermia: Quantitative evaluation of predicted and direct measured temperature distributions in patients with high-risk extremity soft-tissue sarcoma. Int. J. Hyperth. 2019, 169-184. [CrossRef]

21. Sebeke, L.C.; Rademann, P.; Maul, A.C.; Yeo, S.Y.; Castillo Gómez, J.D.; Deenen, D.A.; Schmidt, P.; de Jager, B.; Heemels, W.; Grüll, H.; et al. Visualization of thermal washout due to spatiotemporally heterogenous perfusion in the application of a model-based control algorithm for MR-HIFU mediated hyperthermia. Int. J. Hyperth. 2021, 38, 1174-1187. [CrossRef] [PubMed]

22. Lüdemann, L.; Wlodarczyk, W.; Nadobny, J.; Weihrauch, M.; Gellermann, J.; Wust, P. Non-invasive magnetic resonance thermography during regional hyperthermia. Int. J. Hyperth. 2010, 26, 273-282. [CrossRef] [PubMed]

23. Adibzadeh, F.; Sumser, K.; Curto, S.; Yeo, D.T.B.; Shishegar, A.A.; Paulides, M.M. Systematic review of pre-clinical and clinical devices for magnetic resonance-guided radiofrequency hyperthermia. Int. J. Hyperth. 2020, 37, 15-27. [CrossRef] [PubMed]

24. Feddersen, T.V.; Hernandez-Tamames, J.A.; Franckena, M.; van Rhoon, G.C.; Paulides, M.M. Clinical performance and future potential of magnetic resonance thermometry in hyperthermia. Cancers 2021, 13, 31. [CrossRef]

25. Numan, W.C.M.; Hofstetter, L.W.; Kotek, G.; Bakker, J.F.; Fiveland, E.W.; Houston, G.C.; Kudielka, G.; Yeo, D.T.B.; Paulides, M.M. Exploration of MR-guided head and neck hyperthermia by phantom testing of a modified prototype applicator for use with proton resonance frequency shift thermometry. Int. J. Hyperth. 2014, 30, 184-191. [CrossRef] [PubMed]

26. Winter, L.; Oezerdem, C.; Hoffmann, W.; van de Lindt, T.; Periquito, J.; Ji, Y.; Ghadjar, P.; Budach, V.; Wust, P.; Niendorf, T. Thermal magnetic resonance: Physics considerations and electromagnetic field simulations up to $23.5 \mathrm{Tesla}$ (1 GHz). Radiat. Oncol. 2015, 10, 201. [CrossRef]

27. Han, H.; Oberacker, E.; Kuehne, A.; Wang, S.; Eigentler, T.W.; Grass, E.; Niendorf, T. Multi-channel RF supervision module for thermal magnetic resonance based cancer therapy. Cancers 2021, 13, 1001. [CrossRef]

28. Sumser, K.; Bellizzi, G.G.; Forner, R.; Drizdal, T.; Tamames, J.A.H.; Van Rhoon, G.C.; Paulides, M.M. Dual-function MR-guided hyperthermia: An innovative integrated approach and experimental demonstration of proof of principle. IEEE Trans. Biomed. Eng. 2020, 68, 712-717. [CrossRef]

29. Bellizzi, G.G.; Sumser, K.; Van Rhoon, G.C.; Forner, R.; Paulides, M.M. Feasibility of Integrating an MR Receive Coil Array into the MRcollar. In Proceedings of the 2020 XXXIIIrd General Assembly and Scientific Symposium of the International Union of Radio Science, Rome, Italy, 29 August-5 September 2020; pp. 1-4.

30. Paulides, M.M.; Mestrom, R.M.C.; Salim, G.; Adela, B.B.; Numan, W.C.M.; Drizdal, T.; Yeo, D.T.B.; Smolders, A.B. A printed Yagi-Uda antenna for application in magnetic resonance thermometry guided microwave hyperthermia applicators. Phys. Med. Biol. 2017, 62, 1831. [CrossRef]

31. Fink, M. Time reversal of ultrasonic fields. I. Basic principles. IEEE Trans. Ultrason. Ferroelectr. Freq. Control 1992, 39, 555-566. [CrossRef]

32. Bakker, J.F.; Paulides, M.M.; Westra, A.H.; Schippers, H.; Van Rhoon, G.C. Design and test of a 434 MHz multi-channel amplifier system for targeted hyperthermia applicators. Int. J. Hyperth. 2010, 26, 158-170. [CrossRef] [PubMed]

33. Low, D.A.; Harms, W.B.; Mutic, S.; Purdy, J.A. A technique for the quantitative evaluation of dose distributions. Med Phys. 1998, 25, 656-661. [CrossRef]

34. Goerner, F.L.; Clarke, G.D. Measuring signal-to-noise ratio in partially parallel imaging MRI. Med Phys. 2011, 38, 5049-5057. [CrossRef] [PubMed]

35. Poorter, J.D.; Wagter, C.D.; Deene, Y.D.; Thomsen, C.; Ståhlberg, F.; Achten, E. Noninvasive MRI thermometry with the proton resonance frequency (PRF) method: In vivo results in human muscle. Magn. Reson. Med. 1995, 33, 74-81. [CrossRef]

36. Paulides, M.M.; Bakker, J.F.; van Rhoon, G.C. Electromagnetic head-and-neck hyperthermia applicator: Experimental phantom verification and FDTD model. Int. J. Radiat. Oncol. Biol. Phys. 2007, 68, 612-620. [CrossRef] [PubMed]

37. Paulides, M.M.; Wielheesen, D.H.M.; Van Der Zee, J.; Van Rhoon, G.C. Assessment of the local SAR distortion by major anatomical structures in a cylindrical neck phantom. Int. J. Hyperth. 2005, 21, 125-140. [CrossRef]

38. Bucci, O.M.; Gennarelli, C.; Savarese, C. Representation of electromagnetic fields over arbitrary surfaces by a finite and nonredundant number of samples. IEEE Trans. Antennas Propag. 1998, 46, 351-359. [CrossRef] 
39. Kok, H.P.; Van Haaren, P.M.A.; Van de Kamer, J.B.; Wiersma, J.; Van Dijk, J.D.P.; Crezee, J. High-resolution temperature-based optimization for hyperthermia treatment planning. Phys. Med. Biol. 2005, 50, 3127. [CrossRef]

40. Rijnen, Z.; Bakker, J.F.; Canters, R.A.M.; Togni, P.; Verduijn, G.M.; Levendag, P.C.; Van Rhoon, G.C.; Paulides, M.M. Clinical integration of software tool VEDO for adaptive and quantitative application of phased array hyperthermia in the head and neck. Int. J. Hyperth. 2013, 29, 181-193. [CrossRef]

41. Bellizzi, G.G.; Drizdal, T.; van Rhoon, G.C.; Crocco, L.; Isernia, T.; Paulides, M.M. The potential of constrained SAR focusing for hyperthermia treatment planning: Analysis for the head \& neck region. Phys. Med. Biol. 2018, 64, 015013. [PubMed]

42. Cappiello, G.; Mc Ginley, B.; Elahi, M.A.; Drizdal, T.; Paulides, M.M.; Glavin, M.; O’Halloran, M.; Jones, E. Differential evolution optimization of the SAR distribution for head and neck hyperthermia. IEEE Trans. Biomed. Eng. 2017, 64, 1875-1885. [CrossRef] [PubMed]

43. Köhler, T.; Maass, P.; Wust, P.; Seebass, M. A fast algorithm to find optimal controls of multiantenna applicators in regional hyperthermia. Phys. Med. Biol. 2001, 46, 2503. [CrossRef]

44. Kuehne, A.; Oberacker, E.; Waiczies, H.; Niendorf, T. Solving the time-and frequency-multiplexed problem of constrained radiofrequency induced hyperthermia. Cancers 2020, 12, 1072. [CrossRef] [PubMed]

45. Adibzadeh, F.; Paulides, M.M.; van Rhoon, G.C. SAR thresholds for electromagnetic exposure using functional thermal dose limits. Int. J. Hyperth. 2018, 34, 1248-1254. [CrossRef] [PubMed]

46. Sumser, K.; Bellizzi, G.G.; Van Rhoon, G.C.; Paulides, M.M. The potential of adjusting water bolus liquid properties for economic and precise MR thermometry guided radiofrequency hyperthermia. Sensors 2020, 20, 2946. [CrossRef] [PubMed] 